\title{
Estimating the Number of Dentists Needed in 2040
}

\author{
Stephen A. Eklund, DDS, MHSA, DrPH; Howard L. Bailit, DMD, PhD
}

Abstract: Numerous factors that underlie the need for dentists are undergoing significant changes. Three factors are especially important: 1) improvements in oral health; 2) lower expenditures per patient per year, giving dentists the incentive to treat more patients to maintain incomes that justify their investment in dental education and practice; and 3) dental schools' producing new dentists at a faster rate than the growth in the population. If these trends continue, there is likely to be a dentist surplus of between $32 \%$ and $110 \%$ by 2040 . A major challenge for dental schools is to adjust the production of dentists before 2040 and not wait for market forces to reduce the surplus. Whether there will be a painful market-based solution to the problem, as there was in the 1980 s, or whether a more orderly path can be found is one of the key challenges of the project "Advancing Dental Education in the $21^{\text {st }}$ Century," for which this article was written.

Dr. Eklund is Professor Emeritus, School of Public Health and Adjunct Professor Emeritus, School of Dentistry, University of Michigan; and Dr. Bailit is Professor Emeritus, Department of Community Medicine, School of Medicine, University of Connecticut. Direct correspondence to Dr. Stephen Eklund, 1609 Brooklyn Avenue, Ann Arbor, MI 48104; saeklund@umich.edu.

Keywords: dentists, dental care, health expenditures, oral health, dental schools

Submitted for publication 1/12/17; accepted 3/9/17

doi: $10.21815 / J D E .017 .021$

$\mathrm{T}$ This article examines factors that are likely to affect the number of U.S. dentists needed in 2040 and compares the estimated number of dentists needed in 2040 to the number expected if current trends continue. The article was written as part of the project "Advancing Dental Education in the $21^{\text {st }}$ Century."

As a word of caution, we acknowledge that estimating the number of dentists needed in 2040 is fraught with danger. History is filled with estimates that were wildly inaccurate, including many that seemed eminently reasonable at the time they were made. Further, the number of dentists needed is highly flexible. In the U.S., most dentists decide how many hours they work per year and how much income will satisfy them. The actual time a given dentist spends treating patients over a career that often lasts 40 years or more can be variable in the extreme. In spite of these and other uncertainties, some assessment can be valuable. Important decisions must be made to aid in the development of public policy regarding support for the education of dentists and allied health personnel, and potential students deserve the clearest picture possible of what a future dental career might look like.

\section{Background}

Unlike medicine, dentistry is a profession that is dominated by general practitioners. Whether by design or accident, this pattern seems eminently reasonable. Currently, at least $80 \%$ of dental treatment falls in the categories of routine diagnostic, preventive, and restorative services. ${ }^{1-3}$ Endodontics, periodontics, complex prosthetics, oral surgery, and orthodontics make up the remaining approximately $20 \%$ of treatment. Even within these more specialized categories, general practitioners provide a large proportion of that care.

Current oral health trends show some clear patterns that are likely to affect the need for dentists in the future. A decline in dental caries incidence and severity has been evident since at least the 1970 s. $^{4}$ This decline was first noted in children and, by the 2010 s, was affecting the treatment needs of adults at least into the age group of those in their 50s. ${ }^{1,5}$ These trends have caused a marked drop in the per capita use of nearly all restorative and reparative dental services compared to earlier decades. These trends mean that the number of hours required to treat the "average" dental patient has declined.

Further, the proportion of time spent per patient on routine recall diagnostic and preventive services is now $65 \%$ to $80 \%$ of all dental visits, depending on patient age (Figure 1). ${ }^{1-3}$ This means that, in the average dental practice, over two-thirds of all dental visits require mainly the time of allied dental personnel. This proportion grew at about $1 \%$ per year over the past 20 years, and this has important implications for the needed number and mix of dental personnel. In 2040, dentists will be able to assume responsibil- 


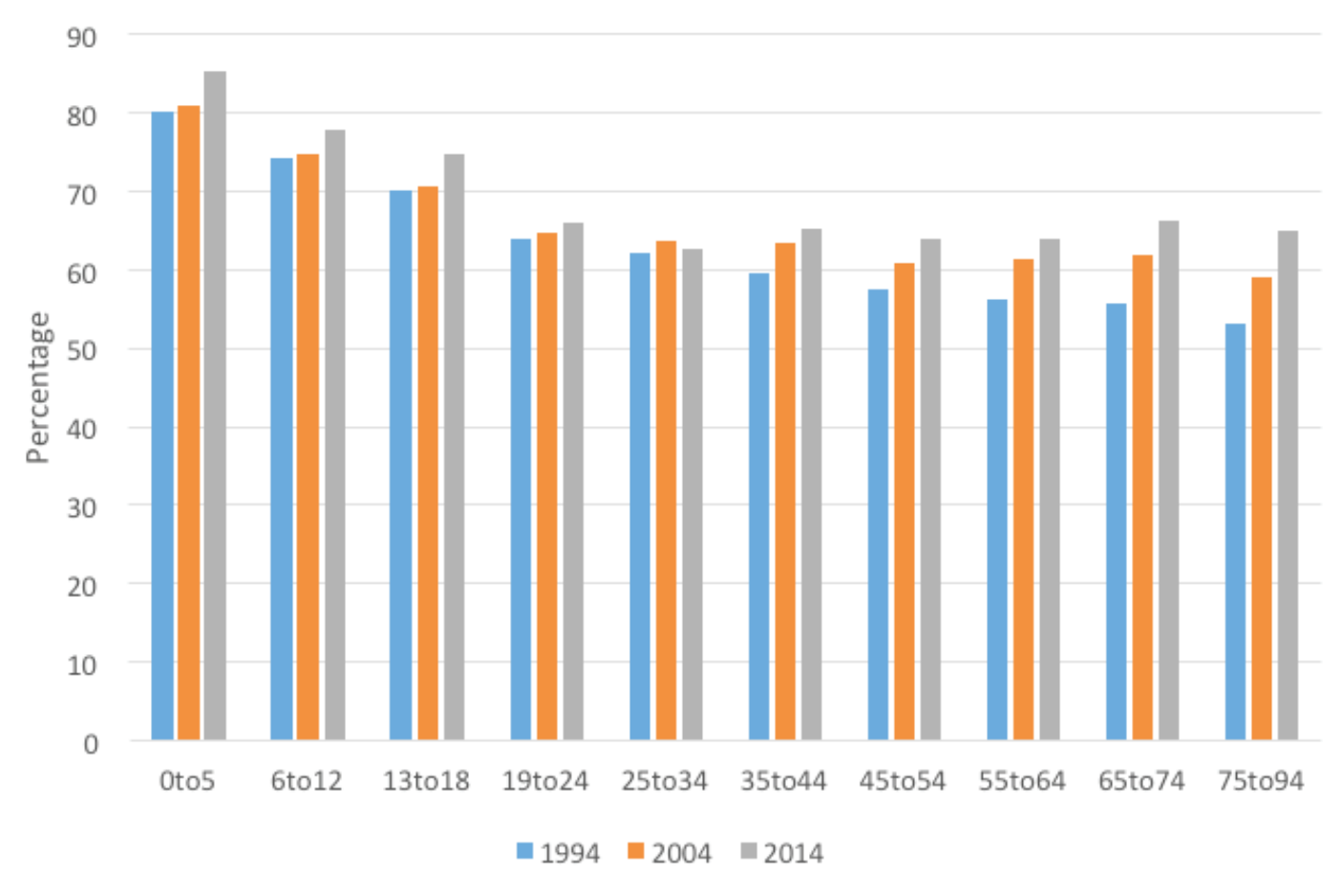

Figure 1. Percentage of total dental visits in Michigan that include only diagnostic and preventive services, by age group for 1994, 2004, and 2014

Source: Analysis of claims from Delta Dental Plan of Michigan by the first author (SAE).

ity for many more patients than has been possible in the past. This projection assumes that the appropriate allied dental personnel are available, practices are organized to accommodate these changes, and sufficient numbers of patients are available.

\section{Methods}

\section{Current Supply of Dentists and Population Demand}

In 2009, there were 195,722 dentists working in the profession (patient care, administration, research/ teaching). ${ }^{6}$ Table 1 shows the percentage and number of full-time equivalent (FTE) dentists working in patient care. Of the 195,722 dentists working in dentistry, $70 \%(136,905)$ provided patient care 30 or more hours per week and are considered full-time.
The available data suggest that between $42 \%$ and $67 \%$ of the population has at least one dental visit in each year. ${ }^{7,8}$ These estimates vary because of differences in estimation methods. The lower estimate comes from patient journals with some follow-up confirmation. The higher estimate comes from selfreporting. As such, Macek et al. believe that the actual value may be closer to the lower estimate. ${ }^{9}$ In any case, with a population of 322 million in the United States in 2015, somewhere between 135,000,000 and 215,000,000 people had at least one dental visit. Therefore, on average, dentists treated between 1,000 and 1,575 patients each year. The former number was seen after the 2007 to 2009 recession. ${ }^{10}$ Whatever the actual number of patients treated annually per dentist, a 2015 American Dental Association (ADA) survey reported that close to $40 \%$ of solo practice dentist owners said they were not as busy as they would like to be. ${ }^{11}$ Thus, many dentists indicated that 


\begin{tabular}{|c|c|c|}
\hline Care Delivery Site & Percentage & Number \\
\hline \multicolumn{3}{|l|}{ Private practice } \\
\hline Full-time & $61.5 \%$ & 120,369 \\
\hline Part-time ${ }^{*}$ & $4.8 \%$ & 9,296 \\
\hline \multicolumn{3}{|l|}{ Other sites } \\
\hline Armed forces & $0.9 \%$ & 1,761 \\
\hline Hospitals & $0.4 \%$ & 782 \\
\hline Resident/graduate student & $1.4 \%$ & 2,740 \\
\hline Other health organization & $1.0 \%$ & 1,957 \\
\hline Total & $70.0 \%$ & 136,905 \\
\hline
\end{tabular}

$* 9.5 \%$ of clinical dentists work less than 30 hours per week. Assuming they work, on average, $50 \%$ time, this is equivalent to $4.8 \%$ of all dentists as full-time.

Source: American Dental Association, Survey Center. Table 13: percentage distribution of all dentists and new dentists in the United States by primary occupation and gender, 2009. In: Distribution of dentists in the United States by region and state. Chicago: American Dental Association, 2010.

they already can manage more patients than they are currently treating.

Among the factors likely to affect the number of patients that each dentist can manage in 2040 are the following ten. First, the oral health of the population in 2040 will be substantially better than in 2015 . This is because most of the pre-fluoride generation will be gone. This group had extensive caries, large restorations, and many missing teeth, and maintaining these compromised dentitions was a major source of practice revenues in the 1980s through the early 2000s. Those born after 1970 have had fewer extractions, root canals, and missing teeth; this is especially true for the upper income population that accounts for about $60 \%$ of practice revenues. ${ }^{12}$ Indeed, in the last 20 years, the utilization of restorations, crowns, extractions, and root canals declined dramatically (as much as 35\% per capita) and will continue to decline. ${ }^{5}$ Removable and fixed prostheses dropped $50 \%$, and full dentures will be virtually non-existent in upper income populations in $2040 .{ }^{13}$ There is an increase in implants, but this service accounts for less than $4 \%$ of practice revenues from privately insured patients and much less from non-insured groups. ${ }^{14}$ With fewer extractions, the future scope for implants would be limited.

Second, children 12 to 18 years of age have remarkably few missing teeth across all income groups, and many missing teeth in upper income children are the result of orthodontic care and do not need to be replaced..$^{15}$ Based on private insurance data, more than $50 \%$ of the permanent teeth extracted are third molars. ${ }^{16}$ Upper income children also have relatively few restored teeth; some $57 \%$ have never had a restoration..$^{15}$ When these children reach adulthood, there will be a significant decline in further restorative care compared to previous cohorts. This is because a major reason for restorations in adult populations is the repair of existing restorations, and the majority of upper income adults will have only a few or no restored surfaces. Another factor is the availability of new technologies to arrest the growth of carious lesions and to remineralize rather than restore lesions in the enamel and outer third of the dentin. Over $50 \%$ of initial lesions that are now restored can be remineralized. ${ }^{17}$ These technologies are now available, but because of the slow rate of dissemination, they may not have a major impact until after 2040. The bottom line is that restorative care-which is now the financial backbone of general dental practice (about $34 \%$ of revenues in privately insured populations) - is certain to be substantially reduced in 2040, both in terms of number of procedures and practice revenues. ${ }^{18,19}$

Third, about $8 \%$ of the population has severe periodontal disease, but these people are concentrated in the lower income adult population and do not have financial access to dental services. ${ }^{19}$ For middle and upper income insured populations, periodontal services account for only about $6 \%$ of practice revenues, ${ }^{14}$ and much of this is for periodic prophylactic maintenance services, usually provided by dental hygienists.

Fourth, the dental delivery system is undergoing a rapid transition from solo to large group practices. Only $50 \%$ of dentists were in solo practice in 2012 , and this decline is likely to accelerate. ${ }^{20}$ By 2040 , perhaps $25 \%$ to $30 \%$ of dentists would be in solo practice. At the same time, large group practices are growing, and many are capitated and at financial risk. They employ dentists who are compensated based, in part, on their compliance with evidencebased clinical guidelines. An example of this type of practice is HealthPartners of Minnesota. This practice reported that its full-time general dentists treat, on average, 2,200 patients per year. ${ }^{10}$ The reasons for this much larger number of patients per dentist are not fully understood but are likely to be related to the greater use of allied health personnel and adherence to evidence-based clinical guidelines. As additional group practices follow the HealthPartners of Minnesota clinical management approach, they are likely 
to achieve similar rates of increased productivity in terms of the average number of patients managed per dentist per year.

Fifth, per capita utilization and expenditures are also expected to grow slowly, if at all. ${ }^{21,22}$ This is because of decline in the percentage of the population enrolled in private dental insurance plans and the reduction in dental benefits for those enrolled. ${ }^{21}$ Another factor reducing growth in per capita utilization rates is a slower growing GDP $(2.5 \%$ vs. $3.5 \%$ per year) and income inequalities. Middle class family incomes have changed little in the past 30 years, so many middle class families cannot afford to purchase dental services with or without private insurance. Also, since a growing proportion of the population has experienced a lifetime with little or no need for restorative services, the use of periodic recall services may be less frequent. The mantra to see your dentist every six months is already being questioned for the patient who has had a lifetime of little or no disease.

Sixth, while there are still significant access and oral health disparities, it is unclear how social policies are likely to change in the next 25 years with respect to providing low-income adults access to basic dental services. If Medicaid-enrolled adults below $250 \%$ of the Federal Poverty Level were provided with basic dental benefits, it would certainly increase utilization rates, at least initially. Nevertheless, since nearly $40 \%$ of dentists report not being as busy as desired ${ }^{11}$ and with the number of dental school graduates expected to reach levels never before seen in the next few years, ${ }^{23}$ the backlog of need could be handled fairly rapidly. Thus, greater demand from low-income adults would likely be well within the capacity of the current care system. Further, if by 2040 most publicly financed dental insurance plans were managed by large capitated group practices (as in Oregon), the cost per patient could be much lower than in current fee-for-service plans. ${ }^{24}$

Seventh, the use of allied dental personnel may begin to provide some restorative care. Nevertheless, we do not think that dental therapists will have much impact on this issue by 2040 except possibly in Minnesota. Few other states have legalized the use of dental therapists, and it would take many years before a large enough number of dental therapists is available to make a significant difference. ${ }^{25}$ Nevertheless, such legislation is periodically being introduced in other states, suggesting that this could change. On the other hand, dental hygienists in many states are providing screening and primary and second- ary preventive services to children in school-based delivery systems and in private practices. As more carious teeth are managed chemically rather than surgically, and even fewer initial restorations need to be replaced either by dentists or dental therapists, dental hygienists would have a greater role in caring for these patients and further increasing the number of patients managed per dentist per year. ${ }^{26}$

Eighth, some primary care medical practices are providing basic screening and preventive dental services to low-income children. ${ }^{27}$ In a few states, some medical practices are employing dental hygienists. This trend is likely to continue, further increasing the supply of dental services.

Ninth, as the services that require dentist-level education decline, a larger percentage of revenues would come from diagnostic and preventive services and the non-surgical management of caries. Since many of these services are now delegated to dental hygienists and dental assistants, the average dentist again would be able to manage a larger number of patients.

Finally, tenth, by 2040 the U.S. population will be about $380,000,000 .{ }^{28}$ This is a growth from $323,000,000$ in $2016 .{ }^{29}$ These extra 57,000,000 people will require some level of dental care, a demand that does not currently exist. However, in addition to the number of people, the age structure of that population is important. The number of people in each birth cohort are not equal, nor are cohort disease experiences the same. The existence of the post-World War II Baby Boom is well known. The number of births in the U.S. from 1946 through 1964 reached levels of well over 4,000,000 per year. ${ }^{30}$ The numbers of births dropped over the subsequent 25 years, to lows of just over 3,000,000 per year in the early 1970s, and did not consistently rise above $4,000,000$ again until the year 2000. Even with the addition of immigrants, this variability results in large age-related peaks and valleys in the size of the U.S. population.

This variability is important because the amount of time required to meet the oral health needs of people depends on their age and disease levels. Those who will be between 76 and 94 years of age in 2040 will be from the postwar Baby Boom. Per capita, these people have had the greatest need for reparative and maintenance care, but their numbers will be rapidly declining. Also, because dental insurance this group often had while working is usually lost at retirement, their ability to pay for extensive dental care would decline. Following the Baby Boomers are people who will be between 40 and 75 years of age. 
In 2040, their per capita disease experience and treatment needs would be lower than it was for the Baby Boomers, and there are nearly a million fewer of them per birth year. ${ }^{30}$ Even though this group is retaining more teeth, the evidence suggests that they require fewer services per capita than prior generations. ${ }^{1,2,5}$ As such, they would generate much less income per patient for dental practices. Those born after 2000, when there were larger birth cohorts again, will be under age 40 in 2040. These individuals would have even less need for care per person and thus likely generate less per capita in dental practice income than any group that preceded them.

\section{Results}

Given these likely future patterns in the population, whatever level of uncertainty there may be in any one of them, collectively they suggest it is reasonable to expect that the average dentist will be able to manage an ever-increasing number of patients. Conservatively, it is well within reason that, by 2040, the average dentist with the use of appropriate allied personnel would care for 2,000 or more patients per year. Of course, these transitions would occur at different rates in different practices and at different locations.

In 2040, the U.S. population is projected to be $380,000,000 .{ }^{28}$ If $42 \%$ of the population uses dental care annually, 160 million Americans would have at least one dental visit that year. Assuming that dentists average 2,000 patients per year in 2040, 80,000 FTE dentists would be needed to provide care to this population. If $67 \%$ of the population seeks care in 2040, 255 million people would require 127,000 FTE dentists.

Based on ADA estimates, there would be about 240,000 dentists in 2040 if current trends continue with no further growth in the number of graduates. ${ }^{23}$ Some $70 \%$ (168,000 dentists) would be in full-time practice. This suggests that the surplus of dentists would likely be between $32 \%$ and $110 \%$. At the extreme, even if every person in the United States were to visit a dentist each year, the dentist surplus would be over $25 \%$.

The numbers involved in these calculations are subject to differing levels of certainty. The U.S. population figures are quite solid, but the estimate of the percentage of the population seeking dental care is less certain. From national surveys, estimates range from $42 \%$ to $67 \%$ and are trending downward, so $67 \%$ is an upper boundary estimate. ${ }^{9}$ The estimate of the number of dentists in 2040 assumes that current trends in graduation rates, foreign-trained dentists, and age of retirement continue. ${ }^{23}$ The estimate of the number of patients treated per dentist per year is likely to be a lower boundary estimate. That is, it could be well above the 2,000 estimates used in this study. These uncertainties aside, our analysis suggests that a large and growing surplus of dentists in 2040 is expected. Regardless of the levels of uncertainty in these figures, the key message is dependent largely on only three of them: 1) the improvements in oral health and their effects moving through the population would result in less need per capita in the population; 2) in response to a lower level of need and thus lower expenditures per patient per year, dentists would adjust their practices to treat more patients in a year to maintain a level of income that justifies their investments of time and money to become dentists; and 3) dental schools would continue to produce new dentists at the current rate. To say that the implications of these projections are staggering is an understatement. As discussed in the next section, we do not believe that current trends in the graduation of dentists will continue and that there will be many fewer dentists in 2040 than previously estimated.

\section{Discussion}

The key policy question is what to do about the potential surplus of dentists? One option is to let the marketplace solve the problem, as it did in the 1980 s. ${ }^{31}$ That is, market competition would result in declining dentist incomes which, in turn, would reduce the number of dental school applicants. This is what happened in the late $1980 \mathrm{~s}$, when the total number of unduplicated applicants nationwide fell well below the number of first-year dental students just a decade before. ${ }^{32}$ With fewer qualified applicants, some schools would close, and many would downsize. With the average debt of dental school graduates approaching $\$ 300,000$ and with static or declining dentist incomes, we believe this is a realistic scenario. ${ }^{33}$

With full recognition of the uncertainties in these calculations, a conservative upper boundary estimate of the number of dental school graduates needed in 2040 is between 3,500 and 5,000 (this assumes an average 35 years in practice). If the annual number of graduates were at steady state of 3,500 to 5,000 since 2005 , this would provide 122,500 to 
175,000 dentists in 2040 . If, as expected, $70 \%$ were in full-time practice ( 30 hours or more per week), this would provide approximately the 80,000 to 127,000 FTE dentists needed in 2040. Of course, the number of graduates has not been stable since 2005 . With a current graduating class of about 6,000 (and growing), ${ }^{23}$ there is already a substantial surplus of dentists, and this surplus would continue for years to come. Importantly, the longer the current number of graduates continue (or grow), the smaller future classes would have to be to correct the imbalance.

While the market would eventually clear the excess capacity, it would have a very adverse impact on thousands of dental graduates who would be unable to realize their expectations for a career or to pay back their large debt. Likewise, faculty and support staff in many dental schools would lose their positions. Unlike in the 1980s, schools have little room to further reduce their operating expenses if they downsized. Major cuts in faculty, physical facilities, and clinical programs started in the 1990s, and there is little left to cut and still meet the educational quality standards required by parent universities and the Commission on Dental Accreditation (CODA). Schools would also have a very difficult time downsizing because they are increasingly dependent on student tuition and fees for operating revenues. Finally, a marketplace solution would jeopardize the position of many dental schools in research-intensive universities because they have a much higher cost structure than other schools.

The alternative is to reduce enrollment before a disruptive market-based solution occurred, but this strategy would have its own set of challenges. First, what specific changes in dental education could lead to major reductions in students, but still keep the basic integrity of dental education in research universities? In Phase 2 of the project "Advancing Dental Education in the $21^{\text {st }}$ Century," a draft set of recommendations on the future of dental education will be developed and sent to key stakeholder organizations and individuals for review. These reviews will be incorporated into the final recommendations advanced by this project. Second, is there still time to make orderly changes in dental education that would prevent a market-based solution? Indeed, if the applicant pool plummeted in the next few years, it could be too late to intervene. Third, it would be difficult to convince the majority of schools to move in a fundamentally new direction on a voluntary basis because no central planning body has control over the decisions of U.S. dental schools. Each school will make decisions that make sense in its own local environment and not on the basis of a national concern. To have a meaningful impact, this project will need to produce a compelling report that quickly gains the support of the major stakeholders.

\section{Editor's Disclosure}

This article is published in an online-only supplement to the Journal of Dental Education as part of a special project that was conducted independently of the American Dental Education Association (ADEA). Manuscripts for this supplement were reviewed by the project's directors and the coordinators of the project's sections and were assessed for general content and formatting by the editorial staff. Any opinions expressed are those of the authors and do not necessarily represent the Journal of Dental Education or ADEA.

\section{REFERENCES}

1. Manski RA, Macek MD, Brown E, et al. Dental service mix among working-age adults in the United States, 1999 and 2009. J Public Health Dent 2014;74:102-9.

3. Manski RJ, Cohen LA, Brown E, et al. Dental service mix among older adults aged 65 and over, United States, 1999 and 2009. J Public Health Dent 2014;74:201-26.

3. Unpublished analysis of private insurance claims by first author (SAE), 2017.

4. U.S. Public Health Service, National Institute of Dental Research. The prevalence of dental caries in United States children, 1979-80. Publication no. 82-2245. Washington, DC: U.S. Government Printing Office, 1981.

5. Eklund SA. Trends in dental treatment, 1992 to 2007 . J Am Dent Assoc 2010;141:391-9.

6. American Dental Association, Survey Center. Table 13: percentage distribution of all dentists and new dentists in the United States by primary occupation and gender, 2009. In: Distribution of dentists in the United States by region and state. Chicago: American Dental Association, 2010 .

7. Manski RJ, Brown E. Dental procedures, United States, 1999 and 2009. Agency for Healthcare Research and Quality statistical brief \#368. 2012. At: meps.ahrq.gov/ mepsweb/data_files/publications/st368/stat368.shtml. Accessed 10 June 2016.

8. National Center for Health Statistics. Table 78: dental visits in the past year, by selected characteristics, United States, selected years 1997-2014. In: Health, United States, 2015: with special features on racial and ethnic health disparities. Hyattsville, MD: National Center for Health Statistics, 2016.

9. Macek MD, Manski RJ, Vargas CM, Moeller J. Comparing health care utilization estimates in the U.S. across three nationally representative surveys. Health Serv Res 2002;37(2):499-521.

10. Gesko DS, Bailit HL. Dental group practice and the need for dentists. J Dent Educ 2017;81(8 Suppl):eS120-5. 
11. Munson M, Vujicic M. General practitioner dentist earnings down slightly in 2014. Research Brief, Health Policy Institute, American Dental Association, 2016. At: www. ada.org/ /media/ADA/Science\%20and\%20ResearchHPI/ Files?HPIBrief_1215_1.ashx. Accessed 14 June 2016.

12. Agency for Healthcare Research and Quality. Table 3.1.a: dental services, mean and median expenses per person with expense and distribution of expenses by source of payment, United States, 2012. Medical Expenditure Panel Survey, Household Component Data. At: meps.ahrq.gov/mepsweb/data_stats/tables_compendia_hh_interactive.jsp?_SERVICE=MEPSSocket0\&_ PROGRAM=MEPSPGM.TC.SAS\&File $=$ HCFY2012\& Table $=$ HCFY2012 $\% 5$ FPLEXP $\% 5$ FB \&VAR $1=$ AGE \&V AR2 $=$ SEX \&VAR3 $=$ RACETH5C\&VAR4=INSURCOV \&VAR5=POVCAT12\&VAR6=MSA\&VAR7=REGION $\&$ VAR $8=$ HEALTH $\&$ VARO $1=4+17+44+64 \& V A R O 2=1$ \&VARO3=1\&VARO4=1\&VARO5=1\&VARO6=1\&VAR O7=1\&VARO $=1 \&$ TCOPT $1=$ GEN\&_Debug. Accessed 16 June 2016.

13. Slade GD, Akinkugbe AA, Sanders AE. Projections of edentulism prevalence following 5 decades of decline. $\mathrm{J}$ Dent Res 2014;93(10):959-65.

14. Personal communication with Dr. Fred Eichmiller, Delta Dental Plan of Wisconsin, 2016.

15. Bailit H, Sungwoo L, Ismail A. The oral health of upper income Americans. J Public Health Dent 2016;76(3): 192-7.

16. Eklund SA, Pittman JL. Third-molar removal patterns in an insured population. J Am Dent Assoc 2001;132:469-75.

17. Brown JP, Amaechi BT, Bader JD, et al. The dynamic behavior of the early dental caries lesion in caries-active adults and implications. Community Dent Oral Epidemiol 2015;43(3):208-16

18. Eklund SA. The impact of improved oral health on the utilization of dental services. J Dent Educ 2017;81(8 Suppl):eS110-9.

19. Rozier RG, White BA, Slade GD. Trends in oral diseases in the U.S. population. J Dent Educ 2017;81(8 Suppl):eS97-109.

20. Guay AH, Wall TP, Peterson BC, Lazar VF. Evolving trends in size and structure of group dental practices in the United States. J Dent Educ 2012;76(8):1036-44.

21. Manski RJ, Meyerhoefer CD. Projecting the demand for dental care in 2040. J Dent Educ 2017;81 (8 Suppl):eS133-45.
22. Nasseh K, Vujicic M. Dental expenditure expected to grow at a much lower rate in the coming years. American Dental Association, Health Policy Institute. At: www.ada. org/ /media/ADA/Science\%20and\%20Research/HPI/ Files/HPIBrief_0813_1.ashx.Accessed 11 June 2016.

23. Munson B, Vujicic M. Number of practicing dentists per capita in the United States will grow steadily. Research Brief, Health Policy Institute, American Dental Association, rev. 2016. At: www.ada.org/ /media/ADA/Science\%20and\%20Research/HPI/Files/HPIBrief_0616_1. pdf. Accessed 22 Feb. 2017.

24. Bailit HL, Plunkett M, Schwartz EW. The Oregon dental market: a case study. J Am Coll Dent 2016;83(2):14-23.

25. Brickle CM, Self KD. Dental therapists as new oral health practitioners: increasing access for underserved populations. J Dent Educ 2017;81(9 Suppl):eS65-72.

26. Fried JL, Maxey HL, Battani K, et al. Preparing the future dental hygiene workforce: knowledge, skills, and reform. J Dent Educ 2017;81(9 Suppl):eS45-52.

27. Silk $H$. The future of oral health care provided by physicians and allied professionals. J Dent Educ 2017;81(8 Suppl):eS171-9.

28. Colby SL, Otrman JM. Projections of the size and composition of the U.S. population: 2014 to 2060. In: Current population reports, P25-1143. Washington, DC: U.S. Census Bureau, 2014.

29. Population Division, U.S. Census Bureau. Table 1: annual estimates of the resident population of the United States regions, states, and Puerto Rico, April 1, 2010 to July 2016. NST-EST2016-01. Washington, DC: U.S. Census Bureau, 2016.

30. Martin JA, Hamilton BE, Osterman MJK, et al. Figure 2: live births and general fertility rates, United States, 1920-2013. In: Births: final data for 2013. Natl Vital Stat Rep 2015;64(1):3.

31. Bailit HL, Beazoglou T. Trends in financing dental education, 2004-05 to 2011-12. J Dent Educ 2017;81 (8 Suppl):eS1-12.

32. American Association of Dental Schools [now American Dental Education Association]. Deans' briefing book, academic year 1988-89. Washington, DC: American Association of Dental Schools, 1989.

33. Asch DA, Nicholson S, Vujicic M. Are we in a medical education bubble market? N Engl J Med 2013;369(212):1973-5. 